\title{
STARK EFFECT AND RESONANCES IN THE IONIZATION CONTINUUM FOR HYDROGEN ATOM AND WANNIER-MOTT EXCITONS IN A DC ELECTRIC FIELD
}

\author{
O. V. Glushkov ${ }^{1}$, S. V. Ambrosov ${ }^{2}$, P. O. Fedchuk ${ }^{3}$, O. P. Fedchuk ${ }^{1}$ \\ ${ }^{1}$ I. I. Mechnikov Odesa National University, a/c 116, Odesa-9, 65009, Ukraine \\ ${ }^{2}$ Odesa State Ecological University, Odesa, 65009, Ukraine \\ ${ }^{3}$ Odesa State Academy of Refrigeration, Odesa, 65026, Ukraine
}

(Received December 16, 2002)

\begin{abstract}
A numerical calculation of the DC Stark effect for hydrogen atom and Wannier-Mott excitons in an external uniform DC electric field is carried out within the operator perturbation theory method. New adequate model for description of the unique especialitites in the photoionization spectra of the hydrogenic atoms is proposed. The positions of the high-excited resonances calculated in the ionization continuum are in a good agreement with known experiment of Glab et al. It is found that the Stark shift for the $n=2$ state of excitons in the $\mathrm{Cu}_{2} \mathrm{O}$ semiconductor (yellow series) at the electric field strength $600 \mathrm{~V} / \mathrm{cm}$ results in $-3.1 \times 10^{-4} \mathrm{eV}$ which agrees well with experimental data of Gross et al. It is indicated also that the analogous unique especialitites may possibly take a place in the Wannier-Mott excitons spectra near the threshold boundary.
\end{abstract}

Key words: atom, Wannier-Mott exciton, Stark effect, photoionization.

PACS number(s): 42.50.-p, 72.20.Jv, 72.40

\section{INTRODUCTION}

Observation of the Stark effect in a constant (DC) electric field near threshold in hydrogen and alkali atoms led to the discovery of resonances extending into the ionization continuum by Glab et al. and Freeman et al. (c.f. [1-8]). Though the known semi-empirical approach of Harmin (c.f. [1-8]) is effective enough, a full adequate consistent theory of this phenomena is absent hitherto. Calculation of the atomic characteristics in a strong electric DC field remains very important problem of modern atomic physics and also of the physics of semiconductors, in particular [1-24].

It is well known [12-16] that the availability of excitons in semiconductors resulted experimentally in the special form of the main absorption band edge and appearance of discrete levels structure (f.e. hydrogen-like spectrum in $\mathrm{Cu}_{2} \mathrm{O}$ ). Beginning from known papers of Gross-Zaharchenya, Thomas and Hopfield et al. (c.f. [7, 15, 23-25]), a calculation procedure of the Stark effect for exciton spectrum attracts a deep interest permanently. As it is well known [24], external electric field shifts and broadens the bound state atomic levels. The standard quantum-mechanical approach mutually relates complex eigen-energies (EE) $E=E_{r}+0.5 i G$ and complex eigenfunctions (EF) to the resonances' shape. The calculation difficulties in the standard quantum mechanical approach are well known [24].

The WKB approximation overcomes these difficulties for the states, lying far from "new continuum" boundary and, as a rule, is applicable in the case of a relatively weak electric field. The same could be regarded to the widespread asymptotic phase method (c.f. [1, 3, $5]$, based on the Breit-Wigner parameterisation for the phase shift dependence on scattering energy. Some modifications of the WKB method were introduced by Popov et al. and Ostrovsky et al. (c. f. [1-5]). Quite another calculation procedures are used in the Borel summation of the divergent perturbation theory (PT) series and in the numerical solution of the difference equations following from expansion of the wave-function over finite basis.

In Ref. [6] a consistent uniform quantum-mechanical approach to the non-stationary state problems solution has been developed including the Stark effect and also the scattering problems. The essence of the method is the inclusion of the well known method of "distorted waves approximation" in the frame of the formally exact PT. The zeroth order Hamiltonian $H_{0}$ of this PT possesses only stationary bound and scattering states. In order to overcome the formal difficulties, the zeroth order Hamiltonian was defined using the set of the orthogonal EF and EE without specifying the explicit form of the corresponding zeroth order potential. In the case of the optimal zeroth order spectrum, the PT smallness parameter is of the order of $G / E$, where $G$ and $E$ are the field width and bound energy of the state level. One could see that $G / E \leq 1 / n$ even in the vicinity of the "new continuum" boundary (where $\mathrm{n}$ is the principal quantum number). This method is called the operator PT (OPT) approach [6].

In Refs. [10, 11] a modified versions of the OPT approach have been developed for solution of the isotopes separation problem and an account of the nonhydrogenic effects was done as well as the improvement of the convergence procedure. It is very important to note that the hamiltonian $H_{0}$ is defined so that it coincides with the general Hamiltonian $H$ at $\varepsilon \rightarrow 0$. ( $\varepsilon$ is the electric field strength). Let us note that perturbation in OPT does not coincide with the electric field potential though they disappear simultaneously. An influence of the corresponding electric potential model function choice on the values of the Stark resonances energies and bandwidths 
does not significantly change the final results for the resonances shifts and widths [6, 11]. All said above regards the Wannier-Mott exciton characteristics in semiconductors as well.

In this paper we have used the OPT method [6] for exact calculation of the DC Stark effect for hydrogen atom and Wannier-Mott excitons in an external uniform DC electric field and the corresponding photoionization spectra. New adequate model for description of the unique especialitites in the photoionization spectra of the hydrogenic atoms is proposed. The positions of the high-excited resonances in the ionization continuum calculated are in a good agreement with known experiment of Glab et al. (c. f. [3, 5]). A case of alkali atoms has been considered in Refs. [7, 8, 15]. It is indicated also that the analogous unique especialitites may possibly take a place in the Wannier-Mott excitons spectra near the threshold boundary.

\section{QUANTUM-MECHANICAL MODEL}

As usually, the Schrödinger equation for the electronic eigen-function taking into account the uniform DC electric field and the field of the nucleus (Coulomb units are used: a unit is $\hbar^{2} / Z e^{2} m$ and a unit of $m Z^{2} e^{4} / \hbar^{2}$ for energy) looks like:

$$
[-(1-N / Z / r+\varepsilon z-0.5 \Delta-E] \psi=0
$$

where $E$ is the electronic energy, $Z$ is charge of nucleus, $N$ is the number of electrons in atomic core. Our approach allow to use more adequate forms for the core potential (c.f. [17-22]), including the most consistent quantum electrodynamics procedure for construction of the optimized one-quasi-electron representation and $a b$ initio core potential, providing a needed spectroscopic accuracy. After separation of variables, equation (1) in parabolic co-ordinates could be transformed to the system of two equations for the functions $f$ and $g$ :

$$
\begin{aligned}
f^{\prime \prime} & +\frac{|m|+1}{t} f^{\prime}+\left[0.5 E+\beta_{1}-N / Z\right) / t \\
& -0.25 \varepsilon(t) t] f=0 \\
g^{\prime \prime} & +\frac{|m|+1}{t} g^{\prime}+\left[0.5 E+\beta_{2} / t+0.25 \varepsilon(t) t\right] g=0
\end{aligned}
$$

coupled through the constraint on the separation constants:

$$
\beta_{1}+\beta_{2}=1
$$

For the uniform electric field $\varepsilon(t)=\varepsilon$. In Ref. [6], the uniform electric field $\varepsilon$ in (3) and (4) was substituted by model function $\varepsilon(t)$ with parameter $\tau\left(\tau=1.5 t_{2}\right)$. Here we use another function, which satisfies to necessary asymptotic conditions (c.f. [11]):

$$
\varepsilon(t)=\frac{1}{t}\left((t-\tau) \frac{\tau^{2}}{\tau^{2}+t^{2}}+\tau\right)
$$

Potential energy in equation (4) has the barrier. Two turning points for the classical motion along the $\eta$ axis, $t_{1}$ and $t_{2}$, at a given energy $E$ are the solutions of the quadratic equation $\beta=\beta_{1}, E=E_{0}$ ). It should be mentioned that the final results do not depend on the parameter $\tau$. It is necessary to know two zeroth order EF of $H_{0}$ : bound state function $\Psi_{E b}(\varepsilon, \nu, \varphi)$ and scattering state function $\Psi_{E s}(\varepsilon, \eta, \varphi)$ with the same EE in order to calculate the width $G$ of the concrete quasi-stationary state in the lowest PT order. Firstly, one would have to define the EE of the expected bound state. It is the well known problem of states quantification in the case of the penetrable barrier. We solve the (2)-(3) set here with the total Hamiltonian $H$ using the conditions [6]:

$$
\begin{aligned}
& f(t)) \rightarrow 0, t \rightarrow \infty \\
& \partial x(\beta, E) / \partial E=0
\end{aligned}
$$

with

$$
x(\beta, E)=\lim _{t \rightarrow \infty}\left[g^{2}(t)+\left\{g^{\prime}(t) / k\right\}^{2}\right] t^{|m|+1} .
$$

These two conditions quantify the bounding energy $E$, with separation constant $\beta_{1}$. The further procedure for this two-dimensional eigenvalue problem results in solving of the system of the ordinary differential equations (2), (3) with probe pairs of $E, \beta_{1}$. The bound state $\mathrm{EE}$, eigenvalue $\beta_{1}$ and $\mathrm{EF}$ for the zero order Hamiltonian $H_{0}$ coincide with those for the total Hamiltonian $H$ at $\varepsilon \rightarrow 0$, where all the states can be classified due to quantum numbers: $n, n_{1}, l, m$ (principal, parabolic, azimuthal) that are connected with $E, \beta_{1}, m$ by the well known expressions. We preserve the $n, n_{1}, m$ states-classification in the $\varepsilon \neq 0$ case. The scattering states' functions must be orthogonal to the above defined bound state functions and to each other. According to the OPT ideology $[6,9,17]$, the following form of $g_{E^{\prime} s}$ is possible:

$$
g_{E^{\prime} s}(t)=g_{1}(t)-z_{2}^{\prime} g_{2}(t)
$$

with $f_{E^{\prime} s}$, and $g_{1}(t)$ satisfying the differential equations (2) and (3). The function $g_{2}(t)$ satisfies the nonhomogeneous differential equation, which differs from (3) only by the right hand term, disappearing at $t \rightarrow \infty$. The coefficient $z_{2}^{\prime}$ ensures the orthogonality condition and could be defined as:

$$
z_{2}^{\prime}=\frac{\iint d \zeta d \eta(\zeta+\eta) f_{E b}^{2}(\zeta) g_{E b}(\eta) g_{1}(\eta)}{\iint d \zeta d \eta(\zeta+\eta) f_{E b}^{2}(\zeta) g_{E b}(\eta) g_{2}(\eta)}
$$


The imaginary part of state energy in the lowest PT order is:

$$
\operatorname{Im} E=G / 2=\pi\left\langle\Psi_{E b}|H| \Psi_{E s}\right\rangle^{2}
$$

with the general Hamiltonian $H$ ( $G$ is resonance width). The state functions $\Psi_{E b}$ and $\Psi_{E s}$ are assumed to be normalized to unity and by the $\delta\left(k-k^{\prime}\right)$-condition, accordingly. The photoionization cross section could be defined as follows:

$$
\sigma^{F}=\frac{4 \pi^{2} \hbar \omega}{137} \sum_{l, l^{\prime}}\left\langle 0\left|r_{m}\right| \Psi_{l^{\prime}}\right\rangle\left[\left\langle\Psi^{\prime} \mid \Psi\right\rangle^{-1}\right]_{l l^{\prime}}\left\langle\Psi_{l}\left|r_{m}\right| 0\right\rangle
$$

where $|0\rangle$ is the initial state of the atom, $r_{m}=z$ for $\pi$-polarized light and $r_{m}=(1 / \sqrt{2})(x \pm i y)$ for $\sigma$-polarization; $\left\langle\Psi_{l}^{\prime} \mid \Psi_{l}\right\rangle$ is the overlap matrix of the set $\{\Psi\}$ (see details of its definition in [4] and references therein). Note then that the whole calculation procedure at known resonance energy $\mathrm{E}$ and separation parameter $\beta$ has been reduced to the solution of one system of the ordinary differential equations. For its solution we use our numeral atomic code [6-9, 15-20]. The calculation results for Stark resonances energies and bandwidths for some states of H atom are presented in Tables 1, 2. For comparison we have indicated the data obtained within another approach - complex eigen-values and numerical calculation [5].

\begin{tabular}{|llll|l|l|l|l|}
\hline$n$ & $n_{1}$ & $n_{2}$ & $m$ & $E$, Ref. [5] & $G$, Ref. [5] & $E$, Present paper & $G$, Present paper \\
\hline 24 & 23 & 0 & 0 & 0.1192 & 0.2752 & 0.1194 & 0.2754 \\
\hline 25 & 23 & 1 & 0 & 0.2748 & 1.0868 & 0.2749 & 1.0871 \\
\hline 25 & 23 & 0 & 1 & 0.8298 & 0.7484 & 0.8301 & 0.7487 \\
\hline 25 & 24 & 0 & 0 & 1.4329 & 0.4175 & 1.4331 & 0.4177 \\
\hline
\end{tabular}

Table 1. The energies $E_{r}$ (atomic units) and widths $G$ (atomic units) of Stark resonances of the hydrogen atom in a DC electric field with strength: $\varepsilon=6.5 \mathrm{kV} / \mathrm{cm}$.

\begin{tabular}{|llll|l|l|}
\hline$n$ & $n_{1}$ & $n_{2}$ & $m$ & $E$, Present paper & $G$, Present paper \\
\hline 24 & 23 & 0 & 0 & 1.9495 & 0.5245 \\
\hline 25 & 23 & 1 & 0 & 2.0397 & 1.6814 \\
\hline 25 & 23 & 0 & 1 & 2.6983 & 1.1878 \\
\hline 25 & 24 & 0 & 0 & 3.3827 & 0.6382 \\
\hline
\end{tabular}

Table 2. The energies $E_{r}$ (atomic units) and widths $G$ (atomic units) of Stark resonances of the hydrogen atom ina DC electric field with strength: $\varepsilon=8.0 \mathrm{kV} / \mathrm{cm}$.

For the most long-living Stark resonances with quantum numbers $n_{2}=0, m=0$, a width of energy level is significantly less than a distance between them. These states are mostly effectively populated by $\pi$-polarized light under transitions from states with $\left(n_{1}-n_{2}\right)=$ $\max , m=0$. As a result, the sharp isolated resonances (their positions under $E>0$ are determined by energies of quasi-stationary states with $n_{2}=0, m=0$ ) are appeared under photo ionization from these states in a case of $\pi$-polarization. In particular, calculated values of photo ionization cross-sections $(\varepsilon=6.5 \mathrm{kV} / \mathrm{cm}):(24,23$, 1, 0) $\sigma^{F}=0.63$ (atomic units), $(24,23,0,0) \sigma^{F}=1.7$ (atomic units) [5].

\section{WANNIER-MOTT EXCITONS IN A DC ELECTRIC FIELD}

The analogous method can be formulated for description of the Stark effect in the Wannier-Mott excitons in semiconductors ( $\mathrm{CdS}, \mathrm{Cu}_{2} \mathrm{O}$ ). The Schrödinger equation for the Wannier-Mott exciton has a standard form:

$$
\left[-\frac{\hbar^{2} \nabla_{e}^{2}}{2 m_{e}^{*}}-\frac{\hbar^{2} \nabla_{h}^{2}}{2 m_{h}^{*}}-\frac{e^{2}}{\varepsilon r_{e h}}-e E r_{e}-e E r_{h}\right] \Psi=E \Psi
$$

Here all notations are standard. A vector potential is as follows: $A(r)=1 / 2[\mathbf{H r}]$. Under transition to system of exciton masses centre by means of introducing the relative coordinates: $r=r_{e}-r_{h}$ 


$$
\rho=\left(m_{e}^{*} r_{e}+m_{h}^{*} r_{h}\right) /\left(m_{e}^{*}+m_{h}^{*}\right)^{\prime},
$$

one could rewrite (9) as:

$$
\begin{aligned}
{\left[-\frac{\hbar^{2} \nabla^{2}}{2 \mu}\right.} & -\frac{e^{2}}{\varepsilon r}-\frac{\hbar}{2}\left(\frac{1}{m_{h}^{*}}-\frac{1}{m_{e}^{*}}\right) \\
& \times K p-e E r] F=\left[E-\frac{\hbar^{2} K^{2}}{8 \mu}\right] F
\end{aligned}
$$

This equation then could be solved by the method, described above. Preliminary estimates show that this approach, in a case of electric DC field, gives the results for Stark states in a reasonable agreement with known results of Thomas and Hopfield (TH) [15]. According to our preliminary estimate, the Stark shift for the $n=2$ state of excitons in the $\mathrm{Cu}_{2} 0$ semiconductor (yellow series) at the electric field strength $600 \mathrm{~V} / \mathrm{cm}$ results in $-3.1 \cdot 10^{-4} \mathrm{eV}$. This value agrees well with experimental data of Gross et al. [23]. Ionization of the exciton in an electric DC field occurs if a change of potential on a small enough distance (the orbits diameter) is comparable with a bonding energy of particle on this orbit. According to data of Gross et al. [23], the corresponding electric field is $\sim 9 \cdot 10^{3} \mathrm{~V} / \mathrm{cm}$. Our calculation agrees with this value. Near ionization boundary, a hydrogen atom demonstrates a behaviour of quantum chaotic system, including the diffusion mechanism of ionization. Besides, for non-hydrogen atoms, there are unique especialitites in the photoionization spectra (alkali atoms). Probably, the analogous unique especialitites may take a place in the Wannier-Mott excitons spectra in semiconductors (of $\mathrm{Cu}_{2} \mathrm{O}$ type) near the threshold boundary. One could suppose very interesting mechanism of the exciton ionization under different values of the electric field strength with possible positive energy resonances in spectra.

\section{CONCLUSIONS}

1. We have demonstrated for the first time the existence of common features in behaviour of such a different physical objects as hydrogen atom, non-hydrogen (alkali) atoms and Wannier-Mott exciton under Stark effect caused by a DC electric field.

2. The calculation procedure seems to be the generator of the states mixture leading to the resonance states ionization threshold lying in the continuum.
[1] Rydberg States of Atoms and Molecules, edited by R. F. Stebbings, F. B. Dunning (Cambridge Univ., New York, 1993).

[2] L. A. Bureeva, V. S. Lisitsa, Vozmuschenny atom (Perturbated Atom) (Atomizd., Moscow, 1996).

[3] V. S. Lisitsa, Usp. Fiz. Nauk bf 1536, 379 (1987).

[4] D. A. Harmin, Phys. Rev. Lett. 49, 128 (1982).

[5] V. V. Kolosov, JETP Lett. 44, 437 (1986).

[6] A. V. Glushkov, L. N. Ivanov, J. Phys. B: At. Mol. Opt. Phys. 26, L379 (1993).

[7] S. V. Ambrosov, Photoelectronics 11, 113 (2001).

[8] S. V. Ambrosov, Uzhgorod Univ. Scientific Herald. Ser. Phys. 8, 131 (2000).

[9] L. N. Ivanov, E. P. Ivanova, L. N. Knight, Phys. Rev. A. 48, 4365 (1993).

[10] A. V. Glushkov, S. V. Ambrosov, I. M. Shpinareva et al., J. Technol. Phys. 38, 215 (1997).

[11] I. I. Shumlyansky, V. G. Shevchuk, V. M. Ignatenko, G. P. Prepelitsa, Uzhgorod Univ. Scientific Herald. Ser. Phys. 8, 372 (2000).

[12] D. Kleppner, I. Chun-Ho, G. R. Welch, Irregular Atomic Systems and Quantum Chaos (Kluwer, New York, 1990).

[13] F. D. Benvenuto, G. Casati, D. L. Shepelyansky, Z. Phys. B. 94, 481 (1994).

[14] Photonic, Electronic, Atomic Collisions, edited by F. Aumayr, H. Winter (World Sci. Pub., Singapore,
1997).

[15] A. V. Glushkov, S. V. Ambrosov, V. M. Ignatenko, Photoelectronics 10, 103 (2001).

[16] A. V. Glushkov, A. P. Fedchuk, I. V. Kuklina, Photoelectronics. 10, 100 (2001).

[17] A. V. Glushkov, l. N. Ivanov, Phys. Lett. A. 170, 33 (1992).

[18] A. V. Glushkov, JETP Lett. 55, 97 (1992).

[19] A. V. Glushkov, L. N. Ivanov, Proc. $3^{\text {rd }}$ Symposium on Atomic Spectroscopy (Nauka, Moscow, 1992).

[20] A. V. Glushkov, S. V. Dan'kov, G. P. Prepelitsa et al., J. Technol. Phys. 38, 219 (1997).

[21] A. V. Glushkov, Electrochemistry 27, 131 (1991).

[22] E. P. Ivanova, L. N. Ivanov, A. V. Glushkov, A. E. Kramida, Phys. Scripta. 32, 514 (1985).

[23] Electron-Hole Drops in Semiconductors, edited by K. D. Jeffriss, L. V. Keldysh (Elseiver, Amsterdam, 1988).

[24] V. M. Agranovich, V. L. Ginzburg, Krystallooptika s uchetom prostranstvennoy dispersii i teoriya exsitonov (Crystals Optics witn Acount of Space dispersion and Theory of Exciton) (Nauka, Moscow, 1979).

[25] M. C. Brodin, I. V. Blonsky, B. M. Nitsovich, B. B. Nitsovich, Dynamicheskie effekty $v$ multicomponentnom gaze kvazichastits (Dynamical Effects in Multicomponent Gas of Quasiparticles) (Naukova Dumka, Kiev, 1990). 


\title{
ЕФЕКТ ШТАРКА ТА РЕЗОНАНСИ В ЙОНІЗАЩӤНОМУ КОНТИНУУМІ ДЛЯ АТОМА ВОДНЮ ТА ЕКСИТОНІВ ВАНЬЕ-МОТТА В ПОСТІӤНОМУ ЕЛЕКТРИЧНОМУ ПОЛІ
}

\author{
О. В. Глушков ${ }^{1}$, С. В. Амбросов ${ }^{2}$, П. О. Федчук ${ }^{3}$, О. П. Федчук ${ }^{1}$ \\ ${ }^{1}$ Одесъкий начіональний університет імені I. I. Мечникова \\ а/с 116, Одеса-9, 65009, Украӥна \\ ${ }^{2}$ Одесъкий держсавний екологічний університет, Одеса-9, 65009, Украйна \\ ${ }^{3}$ Одесъка державна академіл холоду, Одеса-26, 65026, Украйна
}

Методом операторної теорії збурень розраховано ефект Штарка для атома водню та екситонів ВаньєМотта (напівпровідник $\mathrm{Cu}_{2} \mathrm{O}$ ) в однорідному електричному полі. Незвичайні особливості у спектрі фотойонізації воднеподібних систем описані на підставі адекватної квантовомеханічної моделі. Енергії високо розташованих резонансів у йонізаційному континуумі добре узгоджуються з відомими експериментальними даними Глаба і співробітників. Розраховано штарківські зсуви для низки станів екситону в напівпровіднику $\mathrm{Cu}_{2} 0$ (жовта серія) в електричному полі 600 B/см. Результати розрахунку добре узгоджуються з експериментальними даними Гросса і співробітників. Передбачено можливість вияву незвичайних особливостей у спектрах екситонів Ваньє-Мотта поблизу межі йонізації останніх. 